\title{
Evaluation and analysis of climate change on the quantity and quality water resources in Lorestan province (Case study of Khorram river)
}

Reza Hassanzadeh ( $\sim$ rezahassanzadeh608@gmail.com )

Ayatollah Ozma Borujerdi University

Mehdi Komasi

Ayatollah Ozma Borujerdi University

Masoud Ahmadi

Ayatollah Ozma Borujerdi University

\section{Research Article}

Keywords: Index SPI, Drought, Khorram River, WQI Index, Coherence Wavelet

Posted Date: August 3rd, 2021

DOI: https://doi.org/10.21203/rs.3.rs-740864/v1

License: (c) (i) This work is licensed under a Creative Commons Attribution 4.0 International License.

Read Full License 


\title{
Evaluation and analysis of climate change on the quantity and quality water resources in Lorestan province
}

\section{(Case study of Khorram river)}

\author{
Reza Hassanzadeh*1, Mahdi Komasi², Masoud Ahmadi ${ }^{3}$ \\ ${ }^{1}$ Master of water engineering and hydraulic structures, Ayatollah Borujerdi University, Boroujerd, Iran. \\ Email: rezahassanzadeh608@gmail.com. \\ ${ }^{2}$ Associated professor, Department of civil engineering, Ayatollah Borujerdi University, Boroujerd, Iran. \\ Email: komasi@abru.ac.ir. \\ ${ }^{3}$ Assistant Professor, Department of civil engineering, Ayatollah Borujerdi University, Boroujerd, Iran. \\ Email: masoud.ahmadi@abru.ac.ir.
}

"Corresponding author: rezahassanzadeh608@gmail.com

\begin{abstract}
In recent decades due to many droughts many changes have been made in the quantity and quality of the country's water resources. this factor has caused many uncertainties in the management of the country's water resources. The purpose of this study was to improve the understanding of the effects of drought on the quantity and quality of water resources in Lorestsn province in the years 2008 to 2018 by coherence and cross wavelet method. To achieve this goal, first to drought assessment according to precipitation data has been examined using(SPI) index and then the effect of drought on Khorram river water runoff are analyzed. In the next step, the global index of water and the impact of drought on this index in the Khorram river were evaluated. In the next step, the global index of water quality(WQI) and the impact of drought on this index in the Khorram river were evaluated. The results of coherence and cross wavelet indicated which the relative effect of precipitation with a wavelet coherence coefficient of 0.6 on changes in water runoff in the Khorram river is of degree first importance. Also, the relative impact of drought with a wavelet coherence coefficient of 0.4 changes in water quality of Khorram river has been more than other factors. Therefore, climatic factors in reducing the water runoff of Khorram river from factors other are more important. Also, the research results show human factors in changes water quality of Khorram river of degree first importance.
\end{abstract}

Keywords Index SPI, Drought, Khorram River, WQI Index, Coherence Wavelet. 


\section{Introduction}

Rivers are a small part of the world's running water and carry about 32 to 37 cubic kilometers of water to the ocean each year. rivers are one of the main sources of water supply for various purposes such as agriculture, drinking, and industry. Iran is located on the world's drought belt by being in the position of 25 to 40-degree north latitude and for a long time now with the problem of drought, it has been. This subject along with the occurrence of severe and prolonged droughts has created conditions for the country, which has faced serious challenges. Numerous studies have been conducted to identify the effects of drought on the quantity and quality of water resources. For example, Mahmoudi et al. (2016) investigate the effect of drought on the quantity and quality of surface water resources in Sistan and Baluchestan province and showed results that reduce river runoff and rising temperature due to drought caused an increase in the electrical conductivity of water. A comprehensive study has also been conducted on groundwater levels in India. The result also showed that during the drought, there will be changes in water quality in terms of agriculture. In this regard Komasi et al. (2016) examined the routing and classification of factors affecting the reduction of groundwater level by using coherence and cross wavelet in the Silakhor plain. The result of this study showed that the runoff time series, which represents human effects has a greater effect on reducing the aquifer level of Silakhor plain than the precipitation and temperature time series which represents climate change. Also, Soleimani Motlagh et al. (2015) in a study on the aquifer resources of Lorestan province showed that drought has a significant effect on water quality variables such as $\mathrm{Ci}, \mathrm{Na}$, TDS, and $\mathrm{EC}$. one of the important results of this research is that the water quality based on Schuler and Wilcox diagrams has changed due to drought and the quality of drinking water has decreased. Bilesavar et al. (2013) evaluated the effects of drought on groundwater resources in Marand plain using SWI and SPI index. The result of those researchers showed that during the last ten years, the eastern parts of the Marand plain aquifer have had a greater water table drop than the western parts. Also, the trend of declining groundwater levels continues to decline and the continuation of this trend will further reduce the runoff of wells, canals, and spring. Piravi et al. (2015) a study evaluated and analyzed the effects of drought on the water quality of rural wells in the Kashfar area of Mashhad plain. the results showed that the groundwater level decreased quantitatively and qualitatively during the years 2007 to 2011 and there is a significant relationship between changes in water level and water hardness. The results of a study examining the groundwater drought index in the united states have shown that the SPI drought index with a delay of 12 and 24 months has the highest correlation with the SWI index (Tatiana 2019). The research calculated the SPI index using rainfall values and the probability of drought with different drought intensities was investigated and their results showed that this method can be used to predict the occurrence of drought (Paulo et al. 2005). In another study, neural network and regression models were used to predict drought in the Polish-Ethiopian river basin. the results showed that the linear regression model is better than the artificial neural network (Mishra et al. 2012). A comprehensive study has also been conducted on groundwater levels in India. this study examined and analyzed water level in 1002 station before and after the monsoon wind during the statistical period 1943 to 2003. The results showed that the downstream lands 
were not rehabilitated in wet years due to lack of rainfall during dry years, high temperatures, and uncontrolled harvesting during feeding (Dilip et al. 2006). using correlation analysis, the researchers showed that changes in seasonal precipitation in October, November, and December along the coasts of Kenya and Tanzania were highly correlated with the temperature of the Indian ocean between 1950 and 1999 (Clark et al. 2003). On the other hand, Nourani et al. (2015) investigated the changes in hydrological processes using the entropy wavelet criterion in lake Urmia using this criterion, they introduced the reduction of water runoff time fluctuations in the Urmia lake basin as the most important factor in reducing the water level of this lake. To investigate the complexity of the entropy method, he used several scales for rainfall and runoff time series and observed that the results obtained at higher time scales are different from the results obtained at lower time scales (Chou 2014). In the year 2008 Khan et al. in a study of the relationship between drought and groundwater level in one of Australia's plain, concluded that there was a strong correlation between the SPI standard rainfall index and the region's shallow groundwater level.

According to the research background and according to the analysis of data and time series which using reciprocal wavelet transforms and communicational performed with high speed and accuracy, and unlike another method of signal analysis, the trend of sudden changes, breakpoints, and discontinuities can be identified and also due to the comprehensiveness appropriateness of SPI index for monitoring drought from SPI standard precipitation index for drought monitoring and also for to analyze and evaluate the degree of correlation and time range of quantity and quality of

Khorram river water with different factors from coherence and cross wavelet and WQI index have been used.

\section{Material and methods}

\subsection{Case study}

Khorram river is in Khorramabad city and located between the lengths of $47^{\circ} 55^{\prime}$ to $48^{\circ} 50^{\prime}$ east and latitudes $40^{\circ} 32^{\prime}$ to $34^{\circ} 20^{\prime}$ north and at an altitude of 1147 meters above sea level and also, the length of this river is about $110 \mathrm{~km}$, of which about $5 \mathrm{~km}$ passes through the city of Khorramabad (figure1). the city has a temperate and semi-moderate Mediterranean climate, with favorable rainfall, especially in spring. the water of the Khorram river enters through four stations of Bahramjo, Chamanjir, Doabvisian, and Karganeh. the highest and lowest runoff of the Khorramabad river in the years 2008 to 2019 was in 2018 and 2012 respectively. Table 1 shows the statistical characteristics of the study area. 


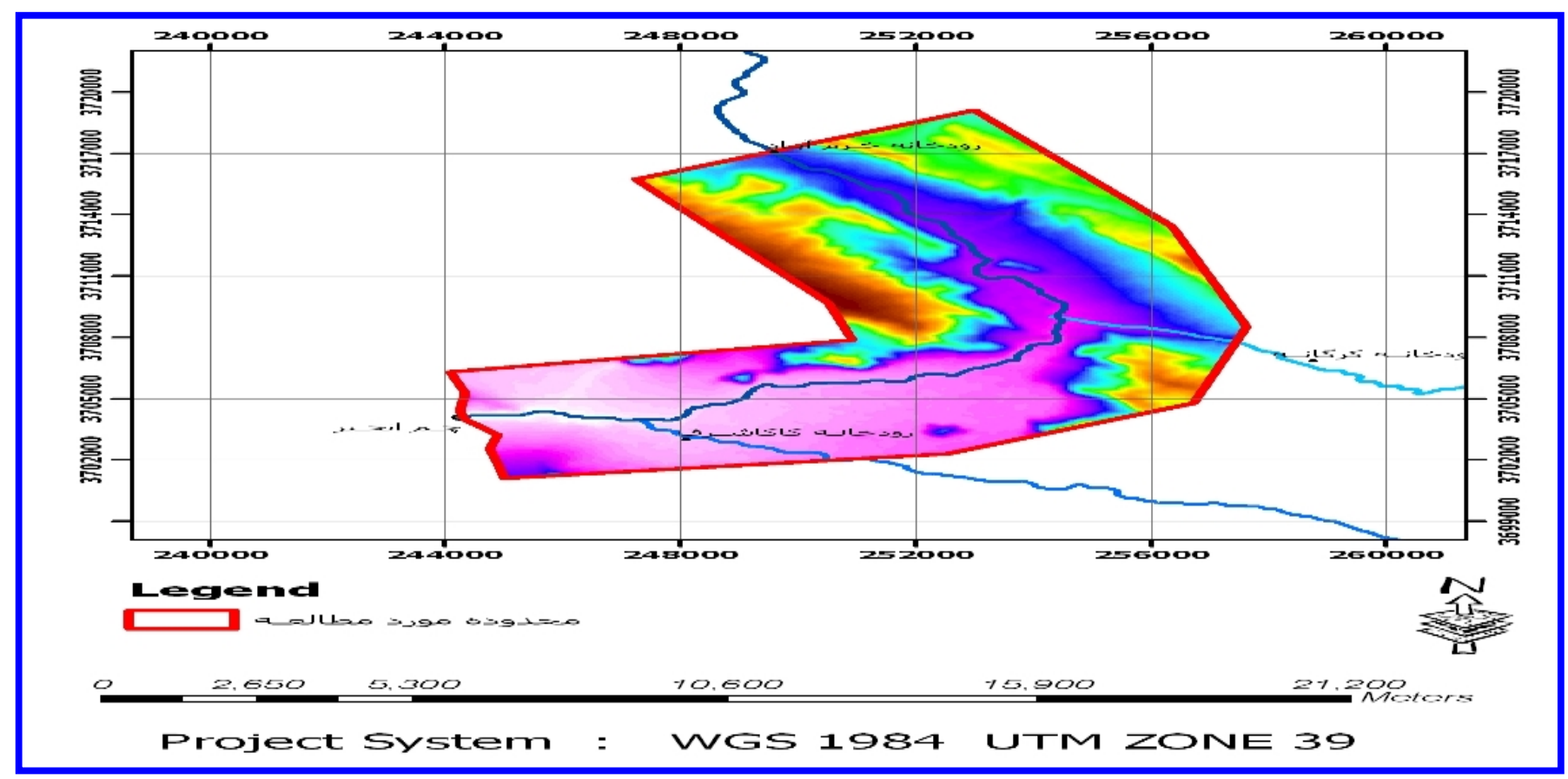

Figure 1 the route of Khorram river

Table 1 Statistical information of the study area in the period of 2008 to 2018

\begin{tabular}{|c|c|c|c|c|c|}
\hline Parameter & Minimum & Maximum & Average & $\begin{array}{l}\text { Standard } \\
\text { deviation }\end{array}$ & Skewness \\
\hline Precipitation $(\mathrm{mm})$ & 0 & 125.5 & 38.1 & 46.5 & 1.5 \\
\hline Temperature (degree Celsius) & -1 & 40.3 & 19.2 & 8.5 & 0.8 \\
\hline Evaporation (mm in month) & 0 & 360.5 & 152.2 & 140.3 & 0.2 \\
\hline Runoff (Cubic meters per second) & 146.5 & 452.1 & 238.2 & 144.7 & 2.2 \\
\hline
\end{tabular}

\subsection{Standard Precipitation Index (SPI)}

The SPI index is a powerful tool in the processing of rainfall data and its purpose is to assign a numerical value to rainfall through which areas with different climates can together be compared. One of the advantages of SPI is that the calculation of SPI is based on rainfall data and does not depend on soil moisture condition, and also another advantage is that this index is not affected by topography (Komasi et al. 2013). In general, this index is defined as to express drought: the period when the SPI is permanently negative and reaches a value -1 or less and when the value is positive. Therefore, positive values indicate above-average rainfall and negative values indicate less rainfall, from average rainfall which is shown in table (2) (Komasi et al. 2013). 
Table 2 drought classification based on SPI index (Hassanzadeh et al. 2012)

\begin{tabular}{cc}
\hline Index values & Drought intensity \\
\hline 2 and more & extremely wet \\
1.5 to 1.99 & very wet \\
1 to 1.49 & Moderately wet \\
-0.99 to 0.99 & Near to normal \\
-1.49 to -1 & Moderately drought \\
-1.99 to -1.5 & very drought \\
-2 and lees & extremely drought \\
\hline
\end{tabular}

The main data of the SPI index are the rainfall data of rain gauge stations. After ensuring the homogeneity and randomness of the monthly data, times series is formed in the intervals of 6 and 12 months, and its time series is fitted with a gamma distribution which is a function of probability density is given in equation (1) (Mckee et al. 1993).

$$
f(x)=\frac{1}{\beta^{\alpha} \Gamma(\alpha)} X^{\alpha-1} e^{-x / \beta}
$$

In this relationship $x \geq 0$ amount of rainfall, $\alpha>0$ shape parameter, $\beta>0$ scale parameter and $\Gamma(\alpha)$ is a function gamma introduced by equation 2 .

$$
(\alpha)=\int_{0}^{\infty} y^{\alpha-1} e^{(-y)} d y
$$

In equation (2), the parameters $\alpha$ and $\beta$ relate to the gamma density function are estimated for each station and for each time scale and for each month of the year. Mckee et al were estimated $\alpha$ and $\beta$ coefficients using the optimal maximum proofing base on equations (3) to (5). (Mckee et al. 1993).

$$
\begin{aligned}
& \alpha=\frac{1}{4 \mathrm{~A}}\left(1+\sqrt{1+\frac{4 \mathrm{~A}}{\mathrm{a}}}\right) \\
& \mathrm{A}=\ln (\overline{\mathrm{X}})-\frac{\sum \ln (\mathrm{X})}{\mathrm{n}} \\
& \beta=\frac{\overline{\mathrm{x}}}{a}
\end{aligned}
$$

In the above equation, $\mathrm{n}$ is the number of rainfall observations and $\mathrm{x}$ is the average rainfall for several months. The calculated parameters to find the cumulative probability of precipitation used for a specific time scale for each station, this probability can be converted to an incomplete gamma function according to equation 6 with the assumption $\mathrm{t}=\mathrm{x} / \beta$.

$$
G(X) \int_{0}^{X} g(X) d X=\frac{1}{\Gamma(\alpha)} \int_{0}^{X} t^{(\alpha-1)} e^{(-t)} d t
$$

Since the gamma function is not defined for $\mathrm{x}=0$, the rainfall distribution has a value of zero the cumulative probability is calculated as equation 7 .

$$
H(X)=q+(1-q) G(X)
$$

The probability of rainfall is zero and $\mathrm{m}$ is the number of zeros in the rainfall time series, which estimates (q) as the product of $m$ divided by the total number of data (n) then having $H(x)$ and relation 8 to 11 , SPI is obtained. 


$$
\begin{array}{lc}
\mathrm{SPI}=-\left[t-\frac{C_{0}+C_{1} t+C_{2} t}{1+d_{1} t+d_{2} t^{2}+d_{3} t^{3}}\right] & 0 \leq \mathrm{H}(\mathrm{X}) \leq 0.5 \\
\mathrm{SPI}=+\left[t-\frac{C_{0}+C_{1} t+C_{2} t}{1+d_{1} t+d_{2} t^{2}+d_{3} t^{3}}\right] & 0.5 \leq \mathrm{H}(\mathrm{X}) \leq 1 \\
\mathrm{t}=+\sqrt{\ln \left(\frac{1}{H(X)^{2}}\right)} & 0 \leq \mathrm{H}(\mathrm{X}) \leq 0.5 \\
\mathrm{t}=+\sqrt{\ln \left(\frac{1}{(1-H(X))^{2}}\right)} & 0.5 \leq \mathrm{H}(\mathrm{X}) \leq 1
\end{array}
$$

In these relation, the coefficients are constant $\mathrm{C}_{0}, \mathrm{C}_{1}, \mathrm{C}_{2}, \mathrm{~d}_{1}, \mathrm{~d}_{2}, \mathrm{~d}_{3}$, should be placed from table 3 in relationships 8 to 11 (Mckee et al. 1993).

Table 3 coefficients values of SPI calculation formulas (Mckee et al. 1993)

\begin{tabular}{ccccccr}
\hline Coefficient & $\mathrm{d}_{1}$ & $\mathrm{~d}_{2}$ & $\mathrm{~d}_{3}$ & $\mathrm{C}_{0}$ & $\mathrm{C}_{1}$ & $\mathrm{C}_{2}$ \\
\hline Value & 1.43 & 0.18 & 0.01 & 2.51 & 0.80 & 0.10 \\
\hline
\end{tabular}

\subsection{Cross Wavelet}

The main purpose of a cross wavelet is to obtaining a complete time-frequency representation of a local and temporary event that varies on time scales. Continuous wavelet transform diagrams are examined to identify periods that offer regions with high wavelet spectra. Cross wavelet diagrams to identify periods that provide areas with high wavelet spectra are examined. According to equation 12 with any desired mother wavelet, such as Morlet's mother wavelet, equation 13 can estimate the wavelet transform for the time series of each of the hydrological data $x(t)($ Labat. 2010).

$$
\begin{aligned}
C_{\psi}^{* x}(a, b) & =\int x(t) \frac{1}{\sqrt{a}} \psi\left(\frac{t-b}{a}\right) \\
\psi_{0}(\eta) & =\pi^{-1 / 4} \mathrm{e}^{\mathrm{i} \omega \eta} \mathrm{e}^{-\eta / 2}
\end{aligned}
$$

$\Psi_{0}$ is a function of the mother wavelet, e exponential function and $\omega$ frequency without dimension and $\eta$ time are dimensionless, also mark "*" refers to mixed mating of the mother wavelet. The parameter " $a$ " is expressed as a scale factor if it is $\alpha>1$, the time series expands along the time axis, and if $\alpha<1$ the time series contracts along the time axis. also, parameter " $b$ " is used as a position factor and allows you to study the time series $x(t)$ around time $b$. the concept of wavelet transform can be used to investigate the relationship between two different time series related to two separate hydrological processes. for this purpose, the wavelet spectrum $\mathrm{W}_{\mathrm{x}}(\mathrm{a}, \mathrm{b})$ of the time series $\mathrm{x}(\mathrm{t})$ is similar to Fourier analysis and is defined by the absolute value of the wavelet coefficient.

$$
\mathrm{W}_{\mathrm{x}}(\mathrm{a}, \mathrm{b})=\mathrm{C}_{\psi}^{x}(a, b) \mathrm{C}_{\psi}^{* x}(a, b)=|\mathrm{cx}(\mathrm{a}, \mathrm{b})|^{2}
$$

This wavelet spectrum can in time also averaging, which is generally defined as the average wavelet power spectrum and allows to specify the scale specification (Torrence et al. 1998). The vacillation alternation period specification is determined using the overall wavelet spectrum. Similar to the Fourier coherence spectrum and wavelet reciprocal spectrum $\mathrm{W}_{\mathrm{xy}}(\mathrm{a}, \mathrm{b})$ between two different hydrological time series $\mathrm{x}(\mathrm{t})$ and $\mathrm{y}(\mathrm{t})$ is defined as follows.

$$
\mathrm{Wxy}(\mathrm{a}, \mathrm{b})=\mathrm{C}_{\psi}^{x}(\mathrm{a}, \mathrm{b}) \mathrm{C}_{\psi}^{* x}(\mathrm{a}, \mathrm{b})
$$


Which $\mathrm{C}_{\psi}^{x}(\mathrm{a}, b)$ and $\mathrm{C}_{\psi}^{* x}(\mathrm{a}, \mathrm{b})$ to order of continuous-time series wavelet coefficients $\mathrm{x}(\mathrm{t})$ and mixed, the wavelet coefficient is $y(t)$. The wavelet spectrum averaging technique is used to express the mutual covariance of time series $\mathrm{x}(\mathrm{t})$ and $\mathrm{y}(\mathrm{t})$ and its distribution at different scales.

\subsection{Coherence wavelet}

The coherence wavelet spectrum was inappropriate for expressing the interrelationship between the two processes and hence the use of coherence wavelet transforms in time series processing which is more appropriate to find a criterion of correlation between two-time series at different frequencies and time (Nourani et al. 2016). in this regard (Torrence. 2011), suggested that the wavelet correlation be determined using wavelet spectrum smooth estimation. Smooth wavelet spectrum $\mathrm{SW}_{\mathrm{xx}}(\mathrm{a}, \mathrm{b})$ and wavelet reciprocal spectrum $\mathrm{SW}_{\mathrm{xy}}(\mathrm{a}, \mathrm{b})$ defined as below:

$$
\begin{gathered}
\mathrm{SW}_{\mathrm{xx}}(\alpha, b)=\int_{t-\delta / 2}^{t+\delta / 2} \quad \mathrm{~W}_{\mathrm{xx}}^{*}(\mathrm{a}, \mathrm{b}) \mathrm{W}_{\mathrm{xx}}(\mathrm{a}, \mathrm{b}) \mathrm{dadb} \\
\mathrm{SW}_{\mathrm{xy}}(\alpha, b)=\int_{t-\delta / 2}^{t+\delta / 2} \quad \mathrm{~W}_{\mathrm{xx}}^{*}(\mathrm{a}, \mathrm{b}) \mathrm{W}_{\mathrm{yy}}(\mathrm{a}, \mathrm{b})
\end{gathered}
$$

In this regard, $\delta$ represent the size of the two-dimensional filter (Luterbacher et al. 2002). Finally, the criterion of coherence wavelet transform relation can also be defined similarly to Fourier coherence as follows:

$$
\mathrm{WC}(\alpha, b)=\frac{|\operatorname{SWxy}(a, b)|}{\sqrt{|S W x x(a, b)| .|S W y y(a, b)|}}
$$

\subsection{Water Quality Index (WQI)}

Water quality index WQI is one of the techniques used to evaluate water quality. This method was first proposed by Horton in the year 1970. this indicates is usually the amount of general parameter of water including dissolved oxygen, acidity, hardness, water-soluble solids, temperature, turbidity, the electrical conductivity of water, nitrite, nitrate, chlorine, and some of the main ions are obtained. Some studies of this statistical technique have been analyzed using the weight score of each parameter, used to evaluate the water quantity index (Toledo et al. 2002) (table 4). The WQI index for easy determines classification water quality in the ratio of numbers less than 50 to more than 300 are considered, which high values indicate lower quality and lower values indicate higher water quality. This method helps to interpret water quality in numerical values. in this study, the parameters $\mathrm{PH}$, TDS, $\mathrm{Ca}, \mathrm{Mg}, \mathrm{Na}, \mathrm{K}, \mathrm{HCO}_{3}, \mathrm{Cl}, \mathrm{SO}_{4}, \mathrm{TH}$, and $\mathrm{EC}$ were used for the WQI index. In WQI index calculation, the first step is weighting, which for each parameter. According to its relative importance, a specific weight is assigned (table 4). The second step is the calculation of relative weight base on equation (19):

$$
\mathrm{W}=\frac{W i}{\sum_{i=1}^{n} W i}
$$

Where, $\mathrm{w}_{\mathrm{i}}$ weight of each parameter $\mathrm{n}$ number of parameters. 
Table 4 Weight ratio of chemical parameters (WHO Standard)

\begin{tabular}{ccccc}
\hline Chemical parameters & Unit & WHO Standard & Weight & Weight ratio \\
\hline $\mathrm{PH}$ & - & $6.5-8.5$ & 4 & 0.129 \\
\hline $\mathrm{TH}$ & $\mathrm{Mg} / 1$ & 200 & 2 & 0.064 \\
\hline $\mathrm{EC}$ & $\mu \mathrm{mhos} / \mathrm{cm}$ & 250 & 3 & 0.096 \\
\hline $\mathrm{Ca}$ & $\mathrm{Mg} / 1$ & 75 & 2 & 0.064 \\
\hline $\mathrm{Mg}$ & $\mathrm{Mg} / 1$ & 50 & 1 & 0.032 \\
\hline $\mathrm{K}$ & $\mathrm{Mg} / 1$ & 12 & 2 & 0.064 \\
\hline $\mathrm{Na}$ & $\mathrm{Mg} / 1$ & 200 & 2 & 0.064 \\
\hline $\mathrm{HCO} 3$ & $\mathrm{Mg} / 1$ & 120 & 3 & 0.096 \\
\hline $\mathrm{Cl}$ & $\mathrm{Mg} / 1$ & 250 & 3 & 0.096 \\
\hline $\mathrm{SO} 4$ & $\mathrm{Mg} / 1$ & 250 & 4 & 0.129 \\
\hline $\mathrm{TDS}$ & $\mathrm{Mg} / 1$ & 600 & 5 & 0.161 \\
\hline Total & - & - & 31 & -
\end{tabular}

The third step is to calculate the quality rate scale. this scale $\left(\mathrm{q}_{\mathrm{i}}\right)$ is calculated by dividing the concentration of each parameter in each water sample by the standard value of that parameter according to equation (20).

$$
\mathrm{q}_{\mathrm{i}}=\frac{\mathrm{c}_{\mathrm{i}}}{\mathrm{s}_{\mathrm{i}}} 100
$$

Which in Ci concentration and Si chemical standard each parameter in the water sample is in $\mathrm{Mg} / \mathrm{l}$. then to estimate WQI, $\mathrm{S}_{\mathrm{i}}$ for each chemical parameter is determined by equation (21) and (22):

$$
\begin{aligned}
& \mathrm{SI}_{\mathrm{i}}=\mathrm{W} \mathrm{q_{ \textrm {i } }} \\
& \mathrm{WQI}=\sum_{\mathrm{i}=1}^{\mathrm{n}} \mathrm{SI}_{\mathrm{i}}
\end{aligned}
$$

Table 5 Water quality classification based on WQI index (Ramakrishanaiah et al. 2009)

\begin{tabular}{cc}
\hline Quality class & Value of the index obtained \\
\hline Unsuitable & 300 \\
\hline Very weak & $200-300$ \\
\hline Weak & $100-200$ \\
\hline good & $50-100$ \\
\hline Excellent & $<50$
\end{tabular}

\section{Result and discussion}

\subsection{Drought index result}

To calculate the drought index, from precipitation data obtained the meteorological organization of Lorestan province has been used. the result of the SPI drought index with an annual scale is shown in figure (2). according to the results of the SPI drought index, it can be said that the Khorram river in the year 2012 in moderately drought, in the years 2016 and 2018 respectively it 
was moderately wet and very wet. in other years, it has a steady and near to normal trend. This indicates that the Khorram river has always been exposed to drought.

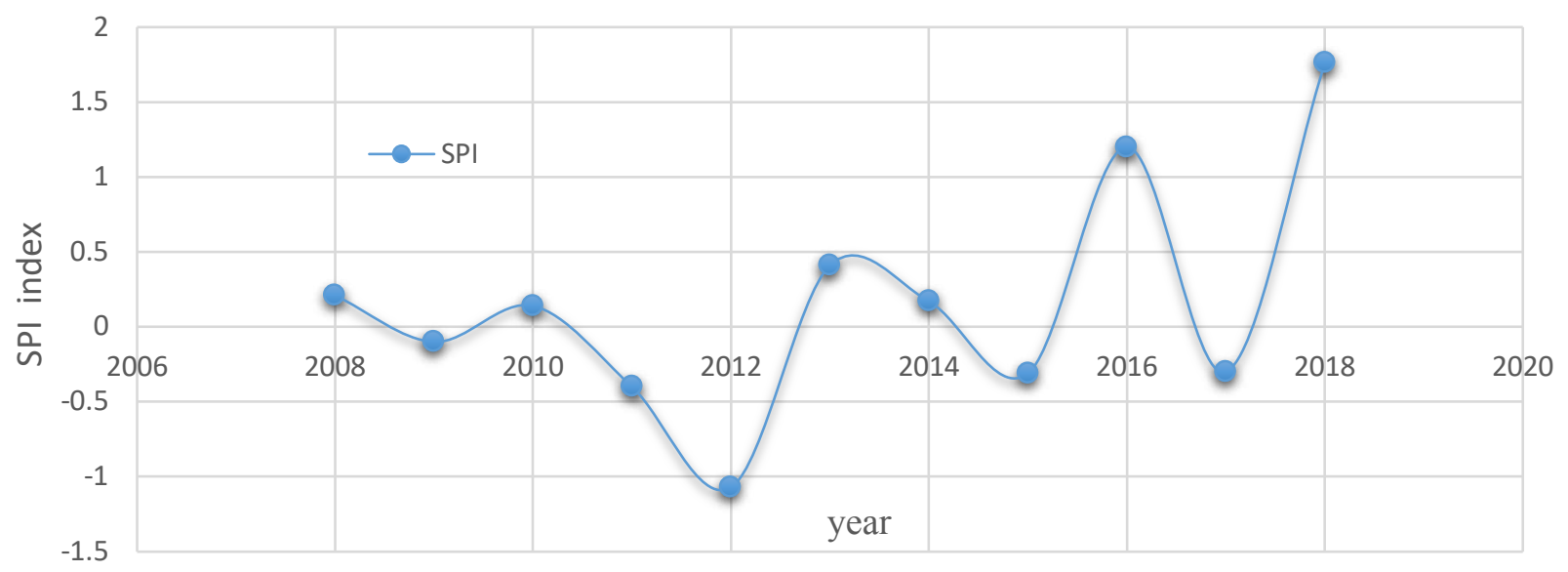

Figure 2 Result of drought in the years 2008 to 2018 in the study area

\subsection{Water Quality Index Results}

To calculate the WQI water quality index from water quality data obtained from the Lorestan province regional water company used. The results of the water quality index with an annual scale are shown in table (6). According to the results, it can be said that the water quality of the Khorram river has been in a favorable condition according to the WQI index in the period of 2008 to 2018. This means that the water of the Khorram river was suitable for drinking, agriculture, and industrial uses. Table 7 shows the results of correlation coefficients of quantitative and qualitative parameters of Khorram River with influencing factors.

Table 6 Values and description of WQI water quality index for the years 2008 to 2018

\begin{tabular}{lcl}
\hline Year & WQI Index & Descriptive equivalent \\
\hline 2008 & 82.23 & good \\
\hline 2009 & 75.38 & good \\
\hline 2010 & 71.13 & good \\
\hline 2011 & 74.75 & good \\
\hline 2012 & 74.46 & good \\
\hline 2013 & 71.76 & good \\
\hline 2014 & 80.13 & good \\
\hline 2015 & 75.27 & good \\
\hline 2016 & 73.59 & good \\
\hline 2017 & 70.60 & good \\
\hline 2018 & 72.12 & good \\
\hline
\end{tabular}


Table 7 Results of correlation coefficients of quantitative and qualitative parameters of Khorram river with influential factors

\begin{tabular}{cccccccccccc}
\hline Index & SPI & Precipitation & $\mathrm{TH}$ & $\mathrm{PH}$ & $\mathrm{Cl}$ & $\mathrm{Ca}$ & $\mathrm{Mg}$ & $\mathrm{SO}_{4}$ & $\mathrm{HCO}_{3}$ & $\mathrm{TDS}$ & $\mathrm{Na}$ \\
\hline $\begin{array}{c}\text { WQI } \\
\text { Quality }\end{array}$ & 0.002 & 0.006 & 0.286 & 0.056 & 0.355 & 0.267 & 0.295 & 0.076 & 0.170 & 0.672 & 0.151 \\
\hline Runoff & 0.36 & 0.209 & 0.089 & 0.070 & 0.14 & 0.103 & 0.006 & 0.022 & 0.070 & 0.001 & 0.015 \\
\hline
\end{tabular}

The result presented in table (7) shows that the highest and lowest correlation in quantitative parameters respectively is runoff-drought and runoff-total dissolved solids in water (TDS). Also, the highest and lowest correlation in quality parameters respectively is quality-total dissolved solids in water (TDS) and quality-precipitation. The results of the correlation table do not show the communication of the quantity's well, so the quantity's communication solution based on coherence and cross wavelet is used.

\subsection{Results of identifying the relationship of time series by coherence and cross wavelet}

In this study, to determine the effect of climatic and human factors on changes the quantity and quality of water Khorram river, four parameters of Precipitation, Runoff, Drought(SPI) and Quality(WQI) were used. Precipitation and drought as a representative of climatic factors and the runoff parameter due to human withdrawals from surface water resources for consumption in agriculture and industry lead to a reduction in water discharge from the region, considered as a representative of the human factor. To evaluate the effect of the mentioned parameters on the changes in the quantity and quality of Khorram river coherence and cross wavelet transforms have been used. Coherence and cross wavelet estimate the amount of interaction and phase delay of two-time series relative to each other. This conversion indicates in what period and with what phase delay the two-time series are related. For this purpose, the time series quality(WQI)precipitation, quality(WQI)-drought(SPI), runoff-precipitation and runoff-drought(SPI) in pair enter the coherence and cross wavelet algorithm that is programmed in Matlab software and the degree of impact and interactions between these time series measured. As the result of coherence and cross wavelet, the areas marked with bold lines and dense arrows are the areas where the coherence and cross wavelet have shown local behavior. This concept means that there is a significant correlation between the corresponding fluctuations of the two-time series in the periodicity (coherence band). arrows to the right indicate that the two-time series same phases and arrows to the left indicate two-time series opposed phases and arrows up or down also mean a time series with a 90-degree angle to another. Figure 3 shows the process of determining the impact of time series on the quantity and quality of Khorram river water by coherence and cross wavelet. The results of coherence and cross wavelet transform for the time series mentioned in figures 4,5 , and 6 are shown. 


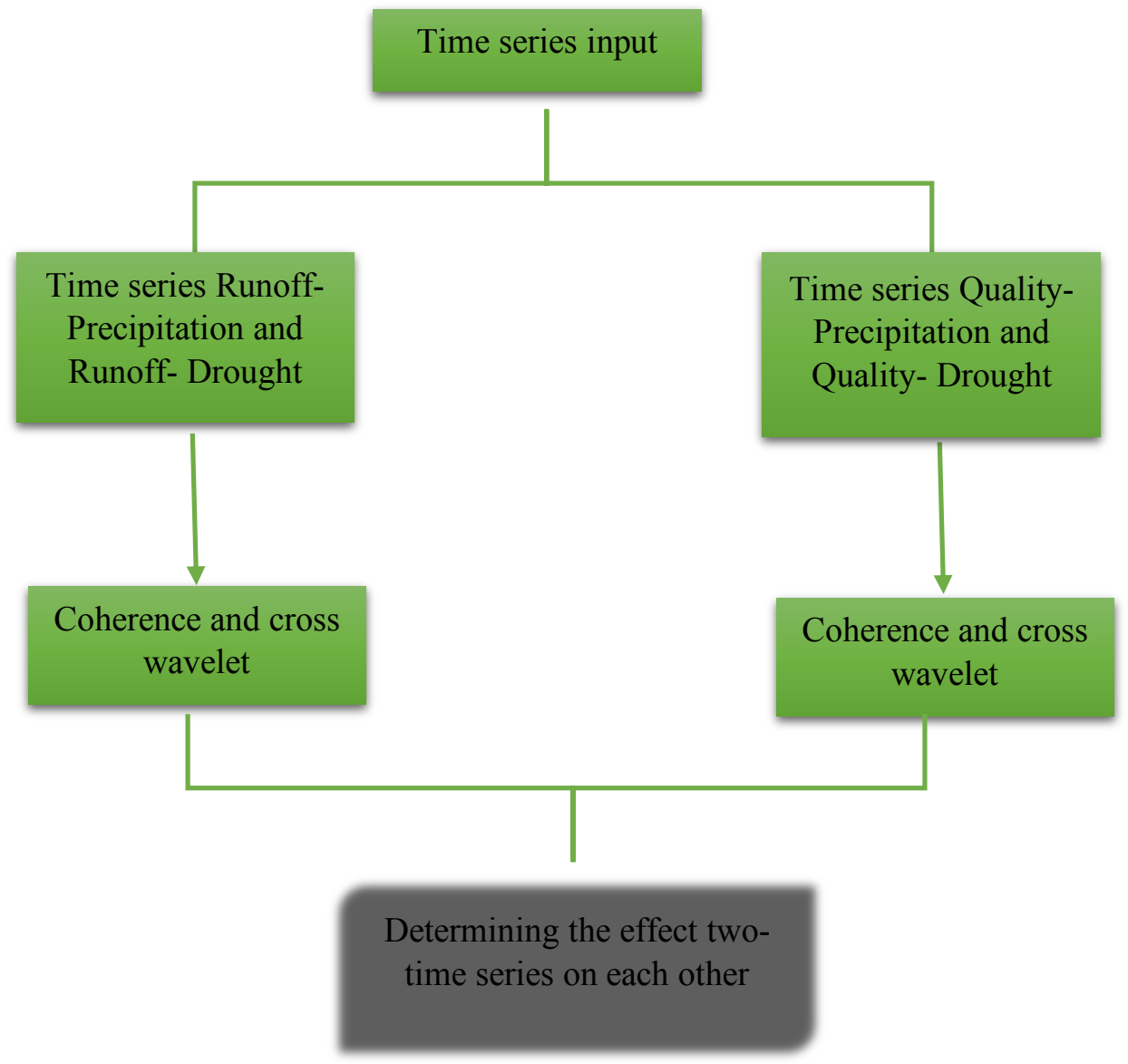

Figure 3 The process of determining the impact of time series on the quantity and quality of Khorram river water by coherence and cross wavelet. 
A

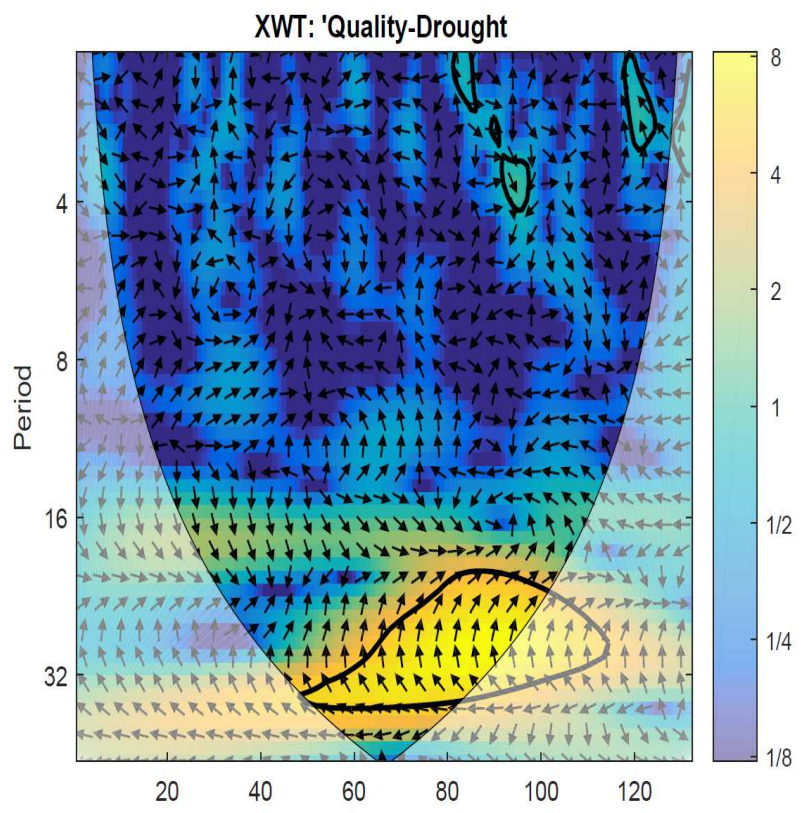

B

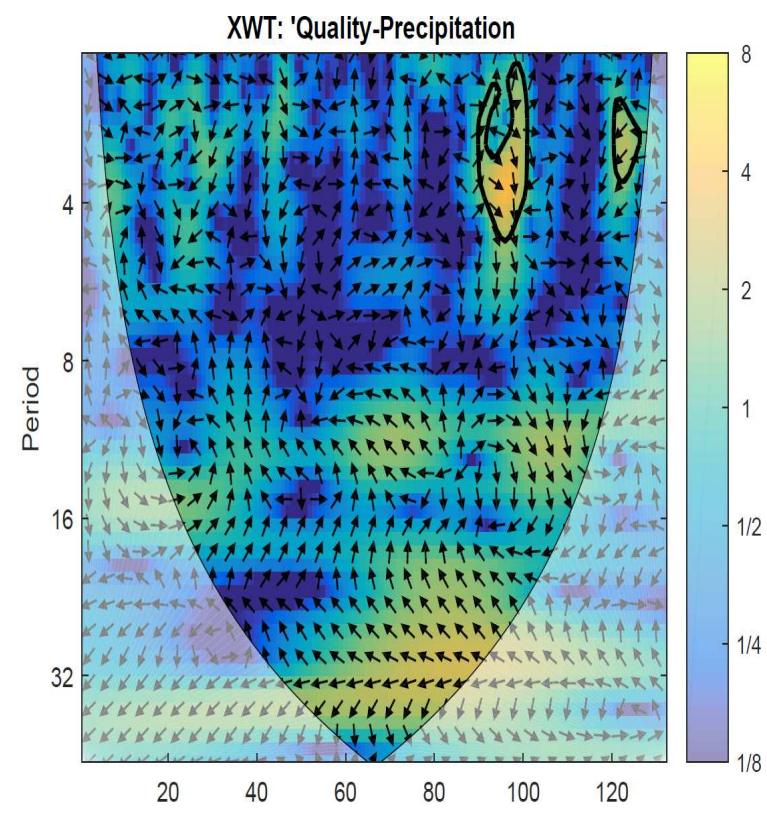

Figure 4 Results cross wavelet transform for time series comparison, A: quality-drought and B: qualityprecipitation.

A

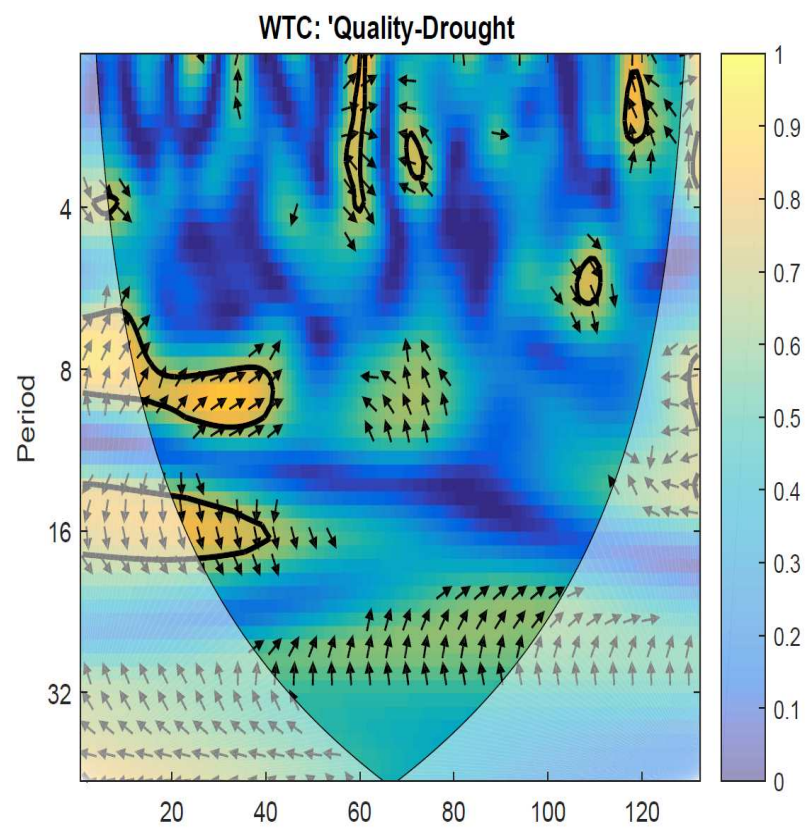

B

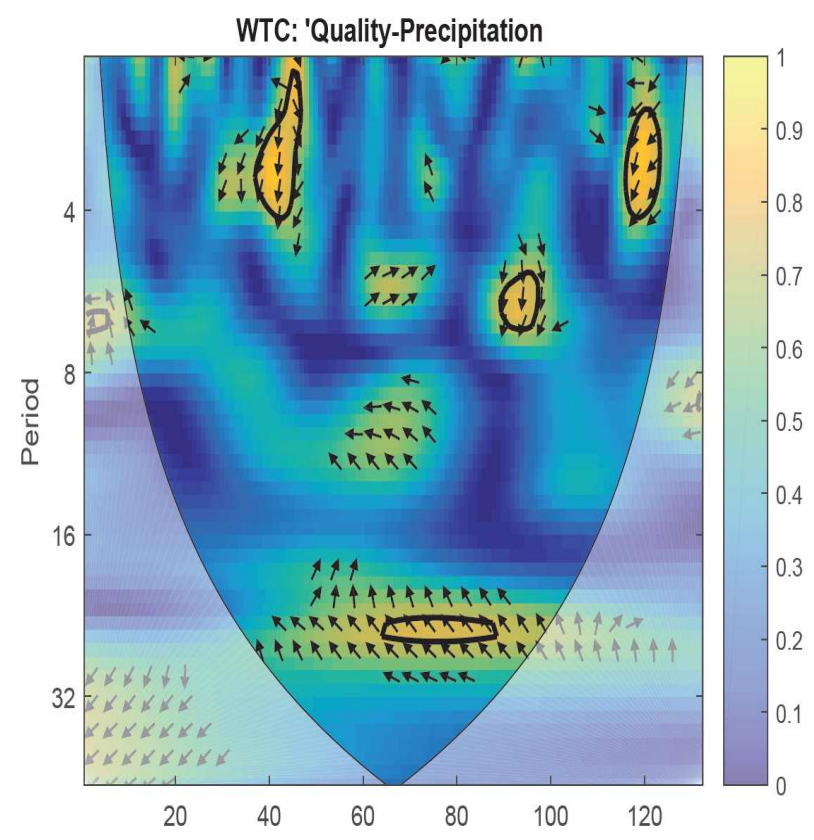

Figure 5 results coherence wavelet transform for time series, A: quality-drought and B: qualityprecipitation. 
In figure 4 coherence wavelet transform two-time series quality-drought with communication band rang in about 16 to 32 months shows. on the other hand, according to figure 5, the wavelet coherence coefficient average obtained from this conversion is estimated to be 0.4 . While the coherence wavelet transforms of two-time series quality-precipitation with band range wavelet transform 16 to 32 months' wavelet transform coefficient 0 f 0.2 has been estimated. The phase difference between the two-time series quality-drought is 90-degrees for the direction of the arrows, which are generally downward. Also the phase different two-time series qualityprecipitation according to the direction of the arrows, which are generally to the left, shows that the two-time series are opposed phase. Based on this interpretation it can be said the relative effect of drought time series compared to precipitation time series on changes in water quality of Khorram river in the period 2008 to 2018 has been more.

A

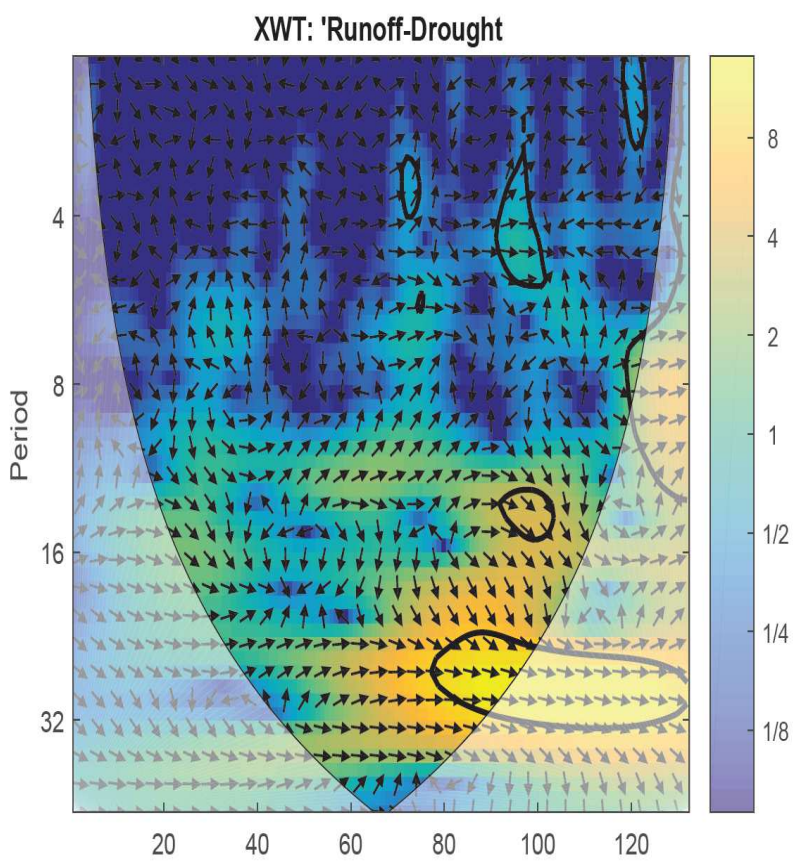

$\mathrm{B}$

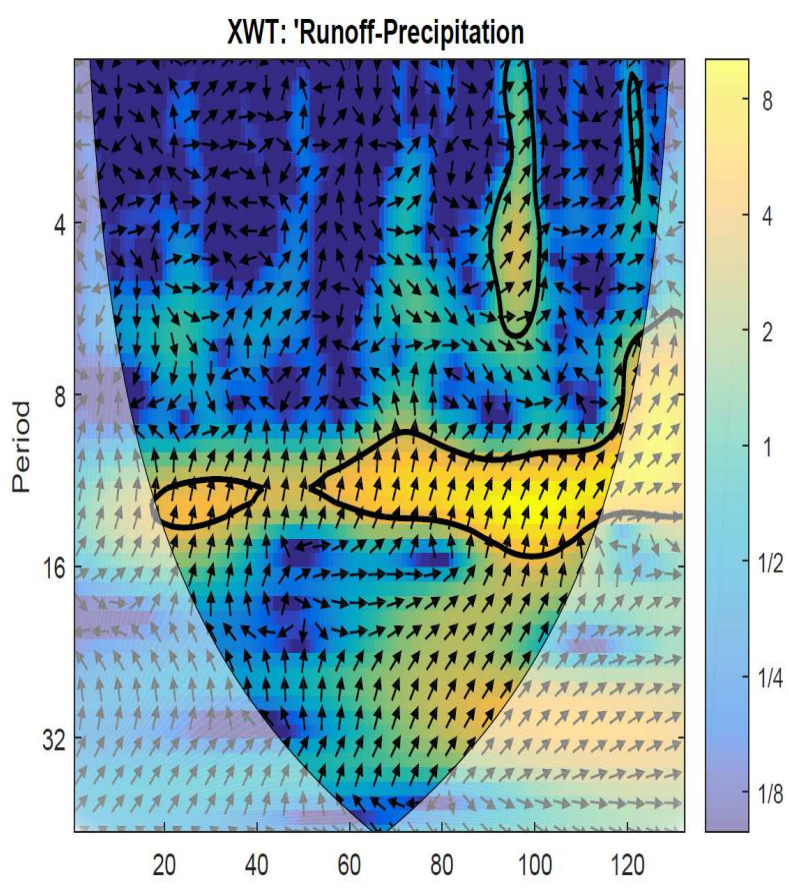

Figure 6 Results cross wavelet transform for time series comparison, A: Runoff-drought and B: Runoffprecipitation. 
A

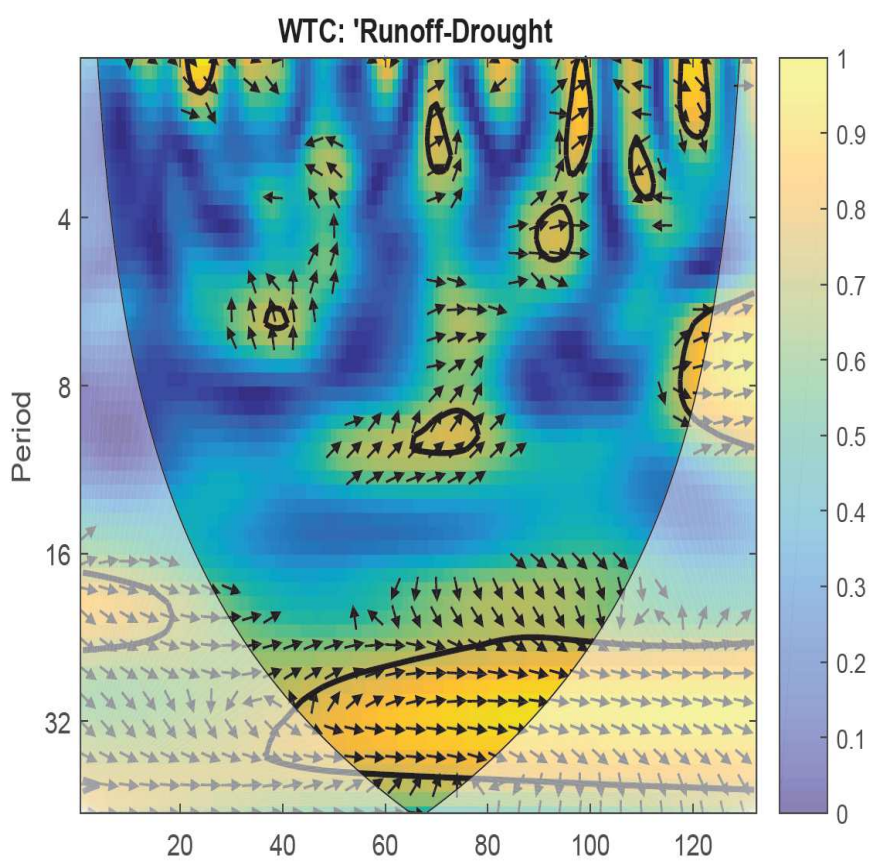

B

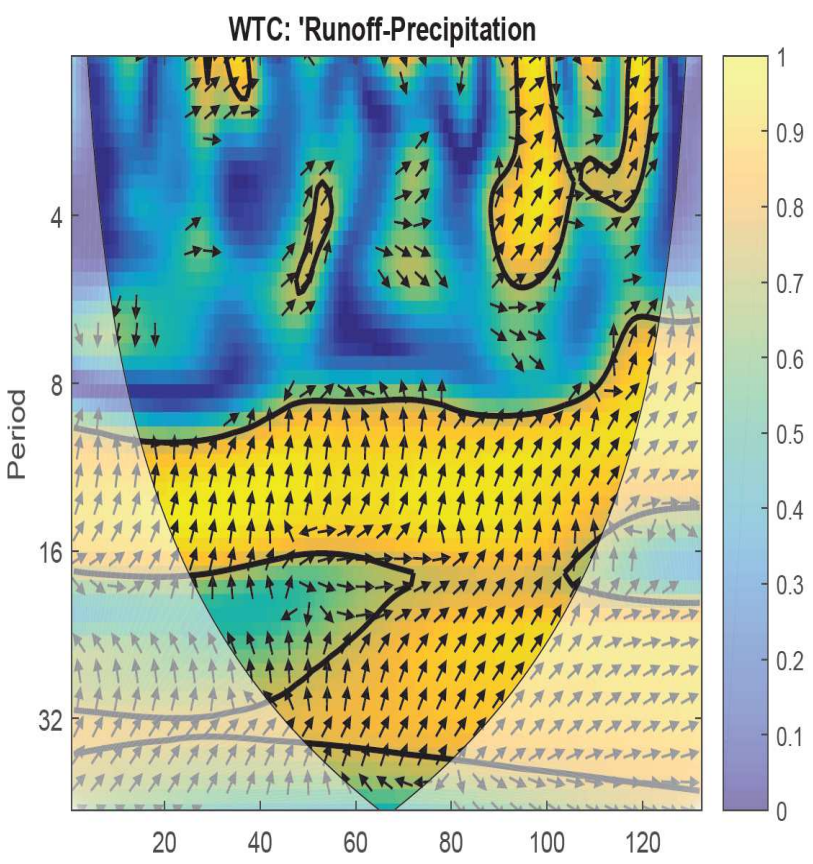

Figure 7 results coherence wavelet transform for time series, A: Runoff-drought and B: Runoffprecipitation.

In figure 6 shows the runoff-precipitation cross wavelet transform, the communication band of the two series about 6 to 15 months. another hand, the average wavelet coherence coefficient obtained from this conversion is estimated to be 0.6. While the cross wavelet transform of the two-time series runoff-drought with a band range of 16 to 32 months has a wavelet coherence coefficient of 0.1. Also, the phase difference between the two-time series runoff-precipitation and runoff-drought according to the direction arrows, which are generally to the right shows the two-time series are in the same phase. based on this interpretation it can be said the relative impact of precipitation time series compared to drought time series on changes in Khorram river runoff in the years 2008 to 2019has been more. table (8) shows the results average wavelet coherence coefficient for hydrological time series.

Table 8 Wavelet coherence coefficient average between Khorram river hydrological time series

\begin{tabular}{ccccc}
\hline Time series & $\begin{array}{c}\text { Runoff- } \\
\text { Drought }\end{array}$ & $\begin{array}{c}\text { Runoff- } \\
\text { Precipitation }\end{array}$ & $\begin{array}{c}\text { Quality- } \\
\text { Drought }\end{array}$ & $\begin{array}{c}\text { Quality- } \\
\text { Precipitation }\end{array}$ \\
\hline $\begin{array}{l}\text { Wavelet coherence } \\
\text { coefficient average }\end{array}$ & 0.1 & 0.6 & 0.4 & 0.2 \\
\hline
\end{tabular}

According to the results of table (8), it can be concluded which the low wavelet coherence coefficient between runoff-drought shows the effect of farmer's uncontrolled withdrawals from 
Khorram river water and the effect of human factors in reducing the water runoff Khorram river. on the other hand, the high wavelet coherence coefficient between runoff-precipitation shows the effect of climatic factors on changes in water runoff in the Khorram river. Also, the high wavelet coherence coefficient quality-drought indicates due to farmer's uncontrolled withdrawals from Khorram river water, the concentration of Khorram river water has also increased as a result the quality of Khorram river water has changed. In a study, Yousefzadeh et al. (2013) studied the water quality of Khorra river with water quality index (NSFWQI) and its zoning with GIS. Their results showed that the water quality of Khorram river had the necessary standard for different uses. It is worth mentioning that the most important parameter that is effective for accurately recognizing time series fluctuations by these two criteria is data continuity. Data continuity means that in the process of changing the time series of hydrological data, there is no discontinuity so that in order to maintain continuity during the time series of unrecorded data, there are no hydrological data during the time series fluctuations. On the other hand, the coherence and cross wavelet criteria deal only with time series, so the physical parameters will have no effect on the results of these two criteria. Figure 8 shows the wavelet coherence coefficient diagram and the correlation coefficient between time series.

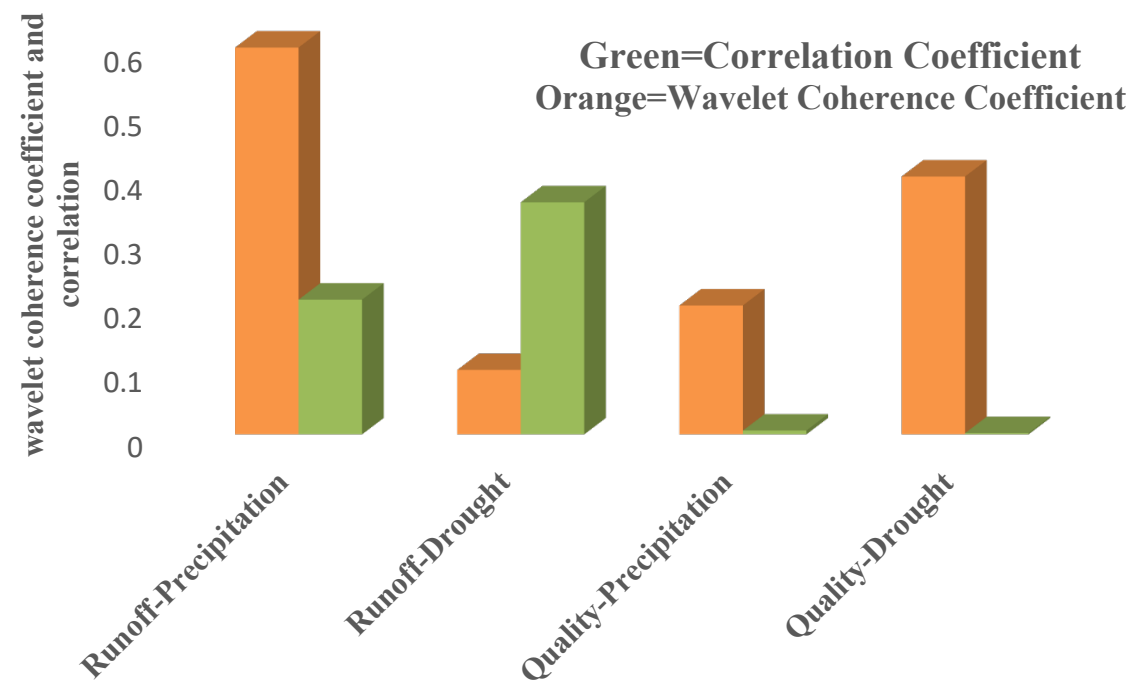

Figure 8 Diagram wavelet coherence coefficient average and correlation coefficient between time series.

\section{Conclusion}

In this research, first, drought analysis according to the SPI drought index based on precipitation data from Lorestan province meteorological organization has been done. the finding showed that in the year 2012, the situation of Khorram river was moderately drought and 2016 and 2018, the situation of Khorram river respectively was in moderately wet and very wet, and in other years it was near to normal. Then the water runoff of the Khorram river and the effects of drought on it have been studied. Study findings showed that the water runoff of the Khorram river has always 
been upward and downward and has not been stable in any year. it should be noted that this issue is one of the significant points and needs attention. The correlation between drought and runoff Khorram river with correlation coefficient is to scale 0.36 . in the next step, the water quality of the Khorram river was analyzed according to the global index (WQI) which the research findings showed the waters entering Khorram river according to the standard of the world health organization (WHO) is in good desirable conditions and is suitable for various uses such as agriculture, drinking, industry and etc. using different methods and criteria to determine and classify the factors affecting the reduction of runoff and quality of aquifers is an effective step towards managing surface water's resources. In this regard, this research has tried to determine the relationship between different parameters on reducing or increasing the runoff rate and quality of the Khorram river water by using coherence and cross wavelet. For this purpose, the degree of impact and interrelationship between the time series of quality-drought and quality-precipitation as well as runoff-drought and runoff-precipitation was determined by coherence and cross wavelet. According to the obtained results, the relative effect of precipitation with a wavelet coherence coefficient of 0.6 on changes in water runoff in the Khorram river was greater. Also, the relative impact of drought with a wavelet coherence coefficient of 0.4 On changes in water quality of the Khorram river has been greater. According to the results of the wavelet coherence on the coefficient of time series, it can be said that farmer's uncontrolled perception of Khorram river water, which shows the impact of human factors, have been more in the changes of Khorram river runoff. Also, this factor cause increased the concentration of water in the Khorram river and as a result, the quality of water in the Khorram river has changed. In completing the present study, it is suggested that the proposed method be applied to daily and annual data to compare the results with the results obtained from monthly data. The use of other criteria and methods of analysis of time series trends such as the Entropy wavelet criterion can be a suitable suggestion to investigate the effects of climate change on the quantity and quality of water resources for future research.

\section{Acknowledgment}

The authors would like to thank the Lorestan Province Regional Water Company for (consultation...).

\section{Compliance with ethical standards}

Conflict of interest On behalf of all authors, the corresponding author states that there is no conflict of interest. Open Access This article is licensed under a Creative Commons Attribution4.0 International License, which permits use, sharing, adaptation, distribution, and reproduction in any medium or format, as long as you give appropriate credit to the original author(s) and the source, provide a link to the Creative Commons license, and indicate if changes were made. The images or other third-party material in this article is included in the article's Creative Commons license unless indicated otherwise in a credit line to the material. If material is not included in the article's Creative Commons license and your intended use is not 
permitted by statutory regulation or exceeds the permitted use, you will need to obtain permission directly from the copyright holder.

\section{Availability of data and materials}

The data that support the findings of this study are available from the corresponding author, [author initials], upon reasonable request.

All authors contributed to the study conception and design. Material preparation, data collection and analysis were performed by [Reza Hassanzadeh], [Mehdi Komasi] and [Masoud Ahmadi]. The first draft of the manuscript was written by [Reza Hassanzadeh] and all authors commented on previous versions of the manuscript. All authors read and approved the final manuscript.

No funding was obtained for this study.

\section{References}

Mahmoudi P, (2016) Drought and its impact on the quality of surface water resources in Sistan and Baluchestan province. journal of water research in agriculture. volume 29. Number 1.

Komasi M and Sharghi S, (2017) Routing and classification of effective in the groundwater level decline using cross and coherence wavelet transform (case study Silakhor plain aquifer). Journal of water engineering [In Iran]. Year 7. Number 28.

Soleimani M and Talebi E, (2015) Investigation of the effects of drought on surface water resources Kashkan. Journal of watershed management [In Iran]. Number 12. pp 154-165.

Bilesavar M and Ahmadzadeh G, (2013) Assessing the effects of drought on groundwater resources in Marand plain. Zagros nation conference on environmental risks [in Iran].

Piravi R and Alidadi H, (2015) Modeling of drought effect on the total hardness and total dissolved solids in ground water of Mashhad plain. Volume 1. Issue 2.

Nourani V and Ranjbar S, Tootoonchi F, (2015) Change detection of hydrological processes using WaveletEntropy complexity measure (case study: Urmia lake). Journal of civil and environmental engineering [In Iran]. Volume 45. Autumn 2015. Issue 3.

Komasi M and Montaseri H, Malek Mahmoudi M, (2017) Drought forecasting by SPI and EDI indices using ANFIS method based C-mean and SC clustering: case study Kohgiluyeh and Boyer Ahmad. Journal of agricultural meteorology. Volume 5. Spring 2017.pp 36-47

Hassanzadeh Y, Lotfollahi M, Shahaverdi S, Farzin S, (2013) De-noising and prediction of time series based on the wavelet algorithm and chaos theory (case study: SPI Drought monitoring indexed Tabriz city). Iran-water resources research. Volume 8. Winter 2013. pp 1-13 
Tatiana E. Gámez, Lisa Benton, Schonna R.Manning. 2019. Observations of two reservoirs during a drought in central Texas, USA: Strategies for detecting harmful algal blooms. Ecological Indicators. Volume 104, September 2019, pp 588-593.

Paul,j.and Amos,N.1998. Smallholder farmers' perceived evaluation of agricultural drought adaptation technologies used in Uganda: Constraints and opportunities. Journal of Arid Environments.

Dilip K. 2006.Impact of drought on the groundwater level of India. Ecological Indicators. Volume 654, October, Pages 500-503

Mishra, A. K. and Singh, V.P., 2011. Drought modeling - A review, Journal of Hydrology, v. 403, p. 157175.

Chou, M.2014.Complexity analysis of rainfall and runoff time Series Based on Sample Entropy in Different Temporal Scales.Stochastic Environmental Research and Risk Assessment, 28:1401-1408.

Makra L, Szilvia H. Effect of evapotranspiration parameterisation on the Palmer Drought Severity Index. Physics and Chemistry of the Earth, Parts $\mathrm{A} / \mathrm{B} / \mathrm{C}$

Volume 35, Issues 1-2, 2010, Pages 11-18.

Khan T. 2008. Standard precipitation index drought and assess impact of rainfall on water tables in irrigation areas. Irrigation drainage system, 22:159-177.

Clark H.2003. Interdicadal variability of relationship between the Indian ocean zonal mode and Est African coastal rainfall anomalies journal of climate, 16:548-554.

Torrence C.2001. Intraseasonal oscillations in sea surface temperature, wind stress, and sea level off the central California coast. Continental Shelf Research.voiume 21, Issues 6-7, April 2001, pp727-750.

Labat P.2010. Cross wavelet analyses of annual continental freshwater discharge and selected climate indices. Journal of Hydrology.Volume 385, Issues 1-4, 7 May 2010, Pages 269-278

Ramakrishnaiah C.R.Sadashivaiah C.and Rangana G.2009. Monitoring of aquatic macro invertebrates as bioindicator for assessing the health of wetlands.Ecological Indicators, 9:118-128. DOI: org/10.1016/j.ecolind.2008.02/004.

Mckee, T.B., Doeken, N.J., and Kleist, J, 1993, The relationship of drought frequency and duration to time scales, $8^{\text {th }}$ conference of of applied climatology, aneheim, 179.184 .

Luterbacher, J., Xoplaki, E., Dietrich, D., Jones, P.D., Davies, T.D., Portis, D., Gonzalez-Rouco, J.F., von Storch, H., Gyalistras, D., Casty, C., Wanner, H., " Extending North Atlantic Oscilation reconstruction back to 1500“ Atmos. Sci. Lett., Vol.2, pp: 114-124, 2002.

Yosefzadeh A. Shams Gh. Godini H. 2013. Investigation of water quality in Khorra river with water quality index (NSFWQI) and its zoning with GIS. Journal of Scientific Research [Iran]. Pp 92-82. 